Fanum

Sociológico

\section{Forum Sociológico}

Série II

$30 \mid 2017$

Internet e ativismos em saúde

\title{
Mais participação, melhor saúde : um caso de ativismo virtual na saúde
}

More participation, better health: a case of virtual activism in health

Sofia Crisóstomo, Ana Raquel Matos, Marta Borges e Margarida Santos

\section{(2) OpenEdition}

\section{Journals}

\section{Edição electrónica}

URL: https://journals.openedition.org/sociologico/1729

DOI: 10.4000/sociologico. 1729

ISSN: $2182-7427$

\section{Editora}

CICS.NOVA - Centro Interdisciplinar de Ciências Sociais da Universidade Nova de Lisboa

\section{Refêrencia eletrónica}

Sofia Crisóstomo, Ana Raquel Matos, Marta Borges e Margarida Santos, «Mais participação, melhor saúde : um caso de ativismo virtual na saúde », Forum Sociológico [Online], 30 | 2017, posto online no dia 30 dezembro 2017, consultado o 30 março 2022. URL: http://journals.openedition.org/ sociologico/1729 ; DOI: https://doi.org/10.4000/sociologico.1729 


\title{
MAIS PARTICIPAÇÃO, MELHOR SAÚDE: UM CASO DE ATIVISMO VIRTUAL NA SAÚDE \\ MORE PARTICIPATION, BETTER HEALTH: A CASE OF VIRTUAL ACTIVISM IN HEALTH
}

\author{
Sofia Crisóstomo \\ Instituto Universitário de Lisboa (ISCTE-IUL), Centro de Investigação e Estudos de Sociologia (CIES-IUL) \& GAT - Grupo \\ de Ativistas em Tratamentos
}

\section{Ana Raquel Matos ${ }^{1}$}

Universidade de Coimbra, Centro de Estudos Sociais (CES)

Marta Borges

GAT - Grupo de Ativistas em Tratamentos

\section{Margarida Santos}

Instituto Universitário de Lisboa (ISCTE-IUL), Centro de Investigação e Intervenção Social (CIS-IUL) \& GAT

- Grupo de Ativistas em Tratamentos

\section{Resumo}

Nos últimos anos, têm surgido novas formas de mobilização, novos atores e novos reportórios de ação, impulsionados pela agenda política e pelo dinamismo crescente da sociedade civil, que reivindica maior participação cidadã. Simultaneamente, a internet assumiu centralidade na relação dos cidadãos com a política e as instituições e como mecanismo de mobilização pelos coletivos e movimentos sociais. O projeto de investigação-ação MAIS PARTICIPAÇÃO, melhor saúde, que tem como objetivo promover a participação dos cidadãos e/ou seus representantes na definição de políticas públicas de saúde e na organização do SNS, é analisado como dinâmica específica de ativismo na saúde em Portugal, na perspetiva da sua estratégia virtual. Os resultados mostram que a internet constituiu uma alavanca fundamental para a mobilização, ação coletiva e sensibilização pública.

Palavras-chave: internet, participação pública, Portugal, saúde

\section{Abstract}

In the last years, new forms of mobilization, new actors and new forms of collective action have emerged, driven by the political agenda and the growing dynamism of civil society, which calls for greater citizen participation. At the same time, internet has taken the center stage in the relationship of citizens with politics and institutions and as a mechanism for mobilization by collectives and social movements. The MORE PARTICIPATION, better health project, which aims at promoting the participation of citizens and/or their representatives in the definition of public health policies and in the organization of the NHS, is analysed in its dynamics as a health collective action in Portugal, in the perspective of its virtual strategy. The results show that the internet was the key for mobilization, collective action and public awareness.

Keywords: internet, public participation, Portugal, health 


\section{Introdução}

Nos últimos anos, transformações relevantes ocorreram nas formas de ação coletiva e nas dinâmicas de ativismo social, processo a que Portugal não ficou alheio. Neste contexto, novas formas de mobilização, novos atores e novos reportórios de ação têm emergido num contexto de mudanças que tem impelido a uma reflexão sobre a relação entre Estado, sociedade civil e participação política. Tais transformações têm permeado com particular vitalidade a área da saúde, o que se pode justificar pelo facto de os sistemas públicos de saúde se terem tornado, depois da Segunda Guerra Mundial, um dos principais pilares do que ficou conhecido pelo Modelo Social Europeu, mas também porque, em Portugal, o Serviço Nacional de Saúde (SNS) é considerado pelos cidadãos como uma das conquistas mais significativas do regime democrático. Considerando que implicados no direito à saúde estão outros direitos - como o da dignidade e o da integridade da vida humana -, a saúde assume-se como domínio das políticas públicas de particular relevância. Decorre deste contexto, não só uma maior abertura por parte do Estado a iniciativas que privilegiam a participação pública nas decisões sobre saúde, como se vem registando também um dinamismo organizativo crescente e inovador por parte da sociedade civil, reivindicando a concretização de mais participação.

O presente artigo visa descrever e analisar uma dinâmica específica de ativismo na saúde em Portugal, designadamente a partir da experiência de um projeto de investigação-ação (IA), o MAIS PARTICIPAÇÃO, melhor saúde (MPms), que enquadra toda uma estratégia assente em formas de ativismo virtual, visando incrementar a participação dos cidadãos e/ou seus representantes na definição de políticas públicas de saúde e na organização do SNS.

O projeto MPms adotou o método de IA, assumido como a melhor opção, considerando o objetivo central visado de desencadear um processo - a partir de uma constante e íntima articulação de membros representantes de associações de pessoas com doença e investigadores - capaz de favorecer a implementação regular e duradoura de espaços de participação pública em decisões sobre saúde. A IA permitiu, neste contexto analítico: i) definir o problema base a tratar; ii) coproduzir conhecimentos relevantes sobre esse problema; iii) desencadear ações específicas orientadas para esse problema; iv) interpretar/avaliar os resultados dessas ações com vista à promoção de uma situação mais justa, sustentável e satisfatória para todos os atores implicados (Greenwood e Levin, 2007; Stringer, 2014). Neste sentido, e tal como defendido por Jürgen Habermas (1973), a investigação realizada teve como firme propósito - recorrendo à criatividade e ao pensamento crítico e emancipatório - promover a mudança e a transformação da realidade da participação na área da saúde.

Este artigo valoriza, assim, a identificação e a análise das estratégias de ativismo virtual adotadas pelo projeto MPms, contextualizando a sua relevância no âmbito das possibilidades de participação pública em saúde em Portugal e avaliando criticamente os seus impactos.

Partindo deste contexto metodológico e analítico, o artigo encontra-se estruturado em seis partes: primeiramente, enquadra-se a participação cidadã enquanto direito legitimado pelo Estado de direito democrático; de seguida, contextualiza-se o ativismo em saúde em Portugal enquanto forma privilegiada de participar em processos decisórios, sobretudo face à escassez de mecanismos institucionalizados que garantam uma participação regular e efetiva nas decisões sobre saúde. Num ponto seguinte, é abordada a dimensão da relação entre internet e saúde na atualidade, para, depois, se apresentar o projeto que sustenta empiricamente este trabalho. Decorre deste alinhamento o ponto seguinte, que descreve e analisa a estratégia de ação adotada pelo projeto MPms para, finalmente, se apresentarem as principais conclusões que emergem da análise efetuada.

\section{A participação pública como direito}

Há cerca de 30 anos que, numa lógica transdisciplinar, abordagens deliberativas e participativas da democracia - assentes em várias possibilidades de participação pública e com impactos distintos nas decisões - têm assumido centralidade em vários domínios científicos, pautando com assertividade as agendas políticas nacionais e internacionais, a partir das quais as instituições políticas têm procurado alargar as oportunidades para envolver os cidadãos na formulação de políticas públicas.

Em Portugal, as várias possibilidades de participação encontram-se consagradas desde a Constituição da República Portuguesa de 1976 (e suas sucessivas alterações) que se seguiu ao regime autoritário. É neste enquadramento democrático que se legitima a participação popular como determinante para a "resolução dos problemas nacionais" (artigo 9.0, alínea c), ao considerar-se que "todos os cidadãos têm o direito de tomar parte na vida política e na direção dos assuntos públicos do país, diretamente ou por intermédio de representantes livremente eleitos" (artigo 48. ${ }^{\circ}$, n. ${ }^{\circ} 1$ ). Não obstante esta garantia normativa da participação pública, a sua operacionalização não tem conseguido espeIhar a clareza e objetividade que Ihe é conferida pela Lei, designadamente porque os imperativos legais da participação não têm encontrado eco na realidade portuguesa, nomeadamente através da 
institucionalização de mecanismos necessários à sua concretização.

A participação da sociedade civil em contextos públicos de decisão, apesar de remeter para uma diversidade de possibilidades, tem vindo assim a elevar-se a verdadeira anáfora nos discursos articulados a partir de intenções políticas, mas também a forte reivindicação por parte da esfera cidadã. Esta polissemia da participação permite introduzir um debate útil aos objetivos do presente artigo, designadamente sobre o que realmente conta como participação. Uma das ferramentas analíticas mais utilizadas na compreensão da participação tem vindo a distinguir entre "participação convencional" e "participação não convencional" (Della Porta, 2007; Meirinho, 2004), distinção coincidente com práticas institucionalizadas e não institucionalizadas de participar em contextos deliberativos. São, assim, consideradas "participação não convencional" as formas de comportamento político em que canais indiretos de influência são abertos através da ação desencadeada por atores coletivos, por exemplo, a ação coletiva a cargo dos movimentos sociais (Della Porta e Diani, 1999: 168 e 192). Embora útil para situar a diversidade de práticas participativas, esta distinção analítica na ação política não passa, portanto, de mera retórica, sobretudo ao ignorar a ação de coletivos e de movimentos sociais enquanto formas legítimas de participar. Tal distinção semântica não deve, portanto, limitar o entendimento deste tipo de iniciativas a formas alternativas às formas convencionais de intervir na política e nos processos públicos de decisão. Neste sentido, as formas convencionais de participação distinguem-se das formas de participação não convencionais também porque estas últimas são, para alguns autores, consideradas ilegítimas ou não consentidas (Meirinho, 2004). Mas também esta se assoma como uma distinção simplista e vaga, sobretudo se atentarmos em contextos democráticos distintos, onde a regulação jurídica destas práticas é variável, já que, dependendo da cultura democrática, a ação coletiva a cargo dos movimentos sociais pode ser uma das únicas formas legítimas de os cidadãos poderem intervir no processo político, razão que leva a que sejam encaradas não como alternativas, mas como formas complementares de participação (Della Porta, 2003; Tilly, 2004).

Também Russell Dalton (1988: 65) ordena as formas de participação num contínuo que abrange a transição da política convencional para a política não convencional. Nesta proposta, a participação através de petições é considerada uma atividade política heterodoxa, mas ainda assim no limite das normas democráticas, ou seja, demarcando a transição para um registo de participação que privilegia o recurso a técnicas de ação direta num contínuo que vai, no limite, até atividades marcadas pela violência. Outros autores, no entanto, consideram o direito de petição participação convencional, estatuto garantido pela legitimidade da defesa de direitos ou do que é definido como interesse geral. Neste contexto, o exercício do direito de petição, além de considerado dos mais antigos direitos de participação que se conhece ${ }^{2}$, assume um âmbito de ação amplo, refletindo a variedade de áreas a partir das quais os cidadãos - organizados individual, coletivamente, ou ainda entidades coletivas - reagem e interagem, por escrito, com diferentes agentes políticos quando afetados pela ação dos poderes públicos (Tibúrcio, 2007). O direito de petição configura uma variedade de orientações da participação, designadamente: a) um pedido dirigido aos poderes públicos, no sentido da tomada de decisões ou da adoção de medidas; b) a representação associada à exposição de "ideias contrárias" ou "chamadas de atenção" em relação a atos praticados pelas autoridades públicas, de forma que estas exerçam um "autocontrolo" ou reflitam sobre os seus efeitos; c) uma queixa, denunciando e dando a conhecer a uma autoridade (geralmente, o superior hierárquico) a prática de um ato ou a adoção de um comportamento ilegal ou o funcionamento anómalo de um serviço, a fim de se poderem adotar medidas adequadas contra o agente ou agentes responsáveis; d) uma reclamação na sua forma típica, ou seja, a impugnação de um qualquer ato de autoridade perante o próprio órgão, funcionário ou agente que o praticou (Canotilho e Moreira, 2007, apud Tibúrcio, 2007: 33).

Neste contexto analítico, o século XXI tem ainda sido marcado por um registo de inovação tecnológica amplamente propiciador de novos canais de comunicação e de formas de ação que têm vindo a acalentar novas expectativas quanto ao exercício de certos direitos, ampliando também estas possibilidades de ação coletiva. Portugal, ainda assim, continua a caracterizar-se pela escassez de oportunidades institucionalizadas para participar. $\mathrm{O}$ caminho traçado tem passado essencialmente pela auto-organização de coletivos de cidadãos, que reivindicam mais espaços para participar em processos públicos de decisão, particularmente sobre matérias que mais diretamente digam respeito às suas vidas.

É, portanto, a participação definida como não convencional aquela que tem assumido maior protagonismo em contexto nacional, designadamente a partir do exercício do direito de reunião, de manifestação e, especialmente, a partir do direito de petição (Mendes e Seixas, 2005; Tibúrcio, 2007).

\section{O ativismo como expressão nobre da participação em saúde em Portugal}

Embora a participação cidadã na área da saúde venha sendo discutida como prioridade a estabelecer em contexto internacional desde 1960, apenas com 
a conferência de Alma-Ata, em 1978, a Organização Mundial de Saúde (OMS) a veio legitimar enquanto preocupação central (WHO, 1978). Desde então, a participação em saúde, entendida como um direito e um dever, tem vindo a ser sistematicamente reiterada em vários documentos oficiais enquanto prioridade que deve ser colocada em marcha (WHO, $1981 ; 1998 ; 2002)$. Não obstante, na generalidade dos casos, esta preocupação ainda não encontra eco em mecanismos institucionalizados, que espeIhem a aplicabilidade do direito à participação em saúde. Portugal não é exceção e dá, por isso, os primeiros passos no sentido da institucionalização de práticas que garantam aos cidadãos e/ou seus representantes a possibilidade de participarem na definição de políticas de saúde.

Desde a publicação da Lei de Bases da Saúde, em 1990 (Lei n.o 48/90, de 24 de agosto), que se prevê a consagração de espaços destinados à participação em saúde em Portugal, embora só muito recentemente o Decreto-Lei n.o 49/2016, de 23 de junho, ou seja, 26 anos depois, tenha vindo prever o regime jurídico do Conselho de Nacional de Saúde (CNS). O CNS constitui um órgão de consulta do governo no âmbito da definição de políticas de saúde, é composto por 30 elementos, dos quais seis são representantes dos utentes eleitos pela Assembleia da República - ainda assim um espaço limitado para a participação na saúde, o qual deveria favorecer uma participação mais alargada da esfera cidadã -, e tem como objetivo "garantir a participação das várias forças científicas, sociais, culturais e económicas na procura de consensos alargados relativamente à política de saúde".

Previamente, o Decreto-Lei n. ${ }^{\circ}$ 28/2008, de 22 de fevereiro, que criou os Agrupamentos de Centros de Saúde (ACES), também previa a participação dos cidadãos num órgão, o Conselho da Comunidade, composto por vários representantes. No entanto, além do atraso e da inoperância relevada em análises recentes, estes órgãos não têm garantido o espaço efetivo à concretização da participação cidadã em saúde (Escoval et al., 2011; Sakellarides et al., 2009).

A escassez de espaços destinados ao envolvimento dos cidadãos na definição de políticas públicas na área da saúde - à semelhança do que, aliás, acontece em outras áreas da vida social em Portugal -, capazes de garantir uma participação efetiva e regular dos cidadãos na definição de políticas públicas, tem condicionado as possibilidades de participação às suas formas ditas não convencionais (Matos, 2016). Esta estratégia de participação, além de legítima, tem vindo assim a cumprir a dupla função de garantir que a participação em saúde acontece nesses mesmos termos, ao mesmo tempo que se luta por mais e melhor participação, numa tentativa de contrariar uma estrutura governativa que se encontra ainda influenciada por uma lógica burocrática e não suficientemente orientada para a participação dos cidadãos (Serapioni, Ferreira e Antunes, 2014). No mesmo sentido, o mais recente relatório do Observatório Português dos Sistemas de Saúde reitera a necessidade de envolver as associações de pessoas com doença, nomeadamente nas políticas e programas para a segurança do doente, facto novo no âmbito do processo de decisão em Portugal, mas que se confronta ainda com várias barreiras, quer do lado da tutela, quer do lado das associações ${ }^{3}$, evidenciando a necessidade de um novo caminho a percorrer (Ferreira et al., 2016: 17).

Uma das maiores interferências notadas na área da saúde, não só em Portugal, como no resto da Europa, tem estado a cargo de coletivos sociais na saúde. Tais coletivos correspondem aos movimentos sociais na saúde, tal como Brown e Zavestoski (2005) os definem, os quais têm vindo a lutar pela promoção e defesa de direitos na área da saúde. No âmbito dessa ação, destaca-se a luta e pressão exercida por estes coletivos, com destaque para as associações de pessoas com doença ou afetadas pela doença, pela abertura de espaços institucionalizados que garantam a participação na defesa de direitos e na redefinição de políticas públicas de saúde (Filipe et al., 2014). Importa, por isso, não negligenciar, enquanto participação, certas formas de ação coletiva. Estas podem desempenhar um papel central no exercício da democracia, ao enquadrarem o direito de participar na tomada de decisões, sobretudo em contextos onde a estrutura governativa ainda falha na provisão de mecanismos e na criação de espaços sustentados de participação cidadã regular e sistemática.

\section{A internet e a saúde}

A internet revolucionou o mundo. É dado adquirido que perante uma pergunta, basta acionar o verbo googlar e esse é um caminho de segundos até uma resposta. Parece, portanto, já não haver curiosidade que não possa ser resolvida à distância de um clique. Desde a dúvida mais simples à situação mais complexa, todas parecem ter resposta online. Um dos temas que mais ocupa motores de busca na internet e redes sociais é, sem dúvida, a saúde (Woolley e Peterson, 2012: 29). A pesquisa online de informações sobre saúde está longe de gerar consensos. Porém, a procura de respostas sobre doença e saúde, incluindo a interação com pares em comunidades virtuais, tem-se imposto face à facilidade de acesso a respostas e à invisibilidade que a internet permite, em particular quando a urgência, a dúvida, a ansiedade ou o medo da discriminação estão presentes. A internet transformou-se, assim, no cenário de fundo que liga os cidadãos à informação e aos vários atores da saúde, sejam profissionais, investigadores, pares individuais ou associações. 
Na saúde, os cidadãos já perceberam o potencial de estar online, transpondo a vida real e as suas comunidades para a rede, com ganhos permanentes em retorno de informação. Por este motivo, a internet tem um papel fulcral na promoção da relação dos cidadãos com as instituições e, desta forma, na sua capacitação para participar no processo de saúde (Espanha, 2013: 14). Ao modelo biomédico vigente, começa gradualmente a impor-se como alternativa, promovida também pela internet, um modelo centrado no cidadão e no seu envolvimento no processo de saúde. Por outro lado, a internet tem ainda um papel fulcral no acesso à informação por parte do cidadão, na promoção da sua relação com as instituições e, desta forma, no seu empoderamento para participar no processo de saúde (Espanha, 2013: 14).

Considerando que o processo de comunicação em saúde valoriza a participação, nomeadamente nas comunidades virtuais, a internet e redes sociais constituem-se como um instrumento para melhorar o acesso à saúde. O cidadão, anteriormente mais passivo relativamente ao seu envolvimento, emerge hoje como um "novo consumidor" (Thomas, 2016: 179). Um cidadão com mais formação académica, com mais conhecimentos em saúde, é assim alguém mais exigente no que concerne à saúde (Espanha, 2013: 29). Este "novo consumidor" de saúde e a utilização das tecnologias de informação na comunicação em saúde têm duas implicações importantes no alcance da comunicação: a primeira prende-se com o facto de as tecnologias aumentarem exponencialmente as pessoas abrangidas pela mensagem de saúde; a segunda, que pode decorrer da primeira, relaciona-se com o aumento das oportunidades de participação do cidadão.

Na pesquisa online de conteúdos relacionados com saúde, nomeadamente nas redes sociais como o Facebook, o cidadão é muitas vezes conduzido a informação lateral àquela que inicialmente procurava. Esta exposição do sujeito a um entrecruzamento de informação pode motivar mais interesse em questões associadas ao tema saúde (Woolley e Peterson, 2012: 36). Assim, as ferramentas de gestão de redes sociais podem tornar-se essenciais para compreender o que leva o cidadão a procurar determinados conteúdos de saúde. Esta informação já determina a disponibilização de determinados conteúdos online, podendo vir a contribuir para a divulgação e criação de novas formas de participação do cidadão no acesso à saúde.

A comunicação em saúde enfrenta assim desafios que podem determinar uma maior adesão do cidadão à informação. Tratando-se de saúde, garantir a qualidade e a fiabilidade da informação disponibilizada é essencial para uma efetiva adesão da comunidade, uma vez que a oferta é dispersa e diversificada. Neste contexto, a questão das frontei- ras e as barreiras linguísticas já não se constituem como problema, dadas as características deste novo consumidor, mas também os desenvolvimentos da própria tecnologia.

Entre os cidadãos que procuram, individualmente, informação sobre saúde, alguns procuram articular-se com outros com quem partilhem os mesmos problemas, embora a internet surja também como instrumento de ativismo para aqueles que já se organizaram fora do espaço virtual a partir de uma causa comum. É neste contexto que as comunidades virtuais tendem a mimetizar comunidades que já existem nas sociedades (Winkelman e Choo, 2003: 353). Os utilizadores da internet não são pessoas que apenas procuram informação ou reconhecimento, são eles próprios atores de um processo que integra a realidade com comunidades virtuais, ou seja, "comunidades que se formam no ciberespaço, atuando como substitutos próximos daquelas que normalmente conhecemos, quando interagimos no mundo real" (Cardoso, 1998: 25). No processo de "procurar saúde" na internet, uma das suas maiores potencialidades, e posteriormente das redes sociais, é justamente o facto de este ser um caminho com múltiplos trajetos, permitindo ao cidadão ir recentrando a sua pesquisa à medida que vai encontrando uma multiplicidade de informação relacionada com seu tema inicial de pesquisa. Tal pressupõe não só aleatoriedade no caminho, mas também interesse no resultado, com o cidadão a estabelecer uma relação diferente com a informação que vai encontrando, consoante o objetivo inicial que motivou a sua procura.

A internet favorece ainda o cruzamento com os já referidos coletivos e movimentos sociais na saúde. No entanto, os cidadãos organizados como um coletivo assumem uma relação diferente com as tecnologias de informação da daqueles que apenas procuram, de forma eventualmente mais passiva, informação sobre saúde. Para Castells (2004: 188), nesta relação do cidadão com a "sua" política, "os cidadãos sentem que não faz muito sentido gastarem as suas energias em situações políticas, exceto quando se veem afetados por um determinado acontecimento que desperta a sua indignação ou afeta os seus interesses pessoais", e esse motor pode ser, de facto, a saúde.

À semelhança de outras organizações na área da saúde, e não só, também as associações de pessoas com doença utilizam as tecnologias ao seu dispor para aumentar a visibilidade das suas causas. Normalmente, as organizações veem nos media e nas redes sociais um megafone para projetar o seu trabalho e reivindicar direitos. As redes sociais onde estão representadas, ainda que geridas muitas vezes de forma não profissional e voluntária, transformaram-se nos melhores expositores públicos destas organizações, permitindo-lhes chegar a um público muito mais vasto. 
MAIS PARTICIPAÇÃO, melhor saúde: exemplo de ação coletiva em saúde

MAIS PARTICIPAÇÃO, melhor saúde (MPms) é um projeto que se concretizou através da iniciativa coletiva de treze associações de pessoas com doença ${ }^{4}$ e uma associação de consumidores, que constituem o Grupo de Trabalho do MPms (GT-MPms) ${ }^{5}$.

Tendo como objetivo promover e alargar a participação dos cidadãos, individuais ou organizados coletivamente (em associações de pessoas com doença, utentes de saúde ou consumidores), no âmbito dos processos de tomada de decisão em saúde, o MPms optou por concentrar a sua ação a nível mesoinstitucional e macropolítico. O MPms assume, assim, como objetivo central da sua ação tornar (mais) participados os processos decisórios relacionados com a política de saúde e com a gestão do SNS, em Portugal, no sentido de garantir um maior envolvimento dos cidadãos afetados ou interessados. É neste contexto que o MPms se tem vindo a consolidar como um coletivo social, tal como definido por Brown e Zavestoski (2005) e Filipe et al. (2014), empenhado na luta pela promoção e institucionalização do direito de participação na saúde em Portugal. Para o efeito, o MPms assume duas linhas prioritárias de atuação: i) a mobilização das pessoas com doença, respetivas associações e outras organizações de defesa do direito e do acesso à saúde, para o ativismo em prol da participação; e ii) a consciencialização de outros atores da saúde para a importância da participação na tomada de decisão.

Desde o lançamento do MPms, em julho de 2015, realizaram-se as seguintes atividades no âmbito das prioridades identificadas anteriormente: i) aplicação de um inquérito por questionário visando a caracterização das visões, atitudes e experiências das pessoas com ou sem doença, e seus representantes, face à participação na decisão política em saúde; ii) elaboração da Carta para a Participação Pública em Saúde (Mais participação, melhor saúde, 2016), iii) realização do Fórum MAIS PARTICIPAÇÃO e organização de uma exposição alusiva à Carta para a Participação Pública em Saúde; iv) promoção de uma petição pública solicitando a discussão da Carta para a Participação Pública pela Assembleia da República; e v) participação em reuniões científicas e conferências sobre saúde, para apresentação do MPms, promovendo a participação pública em saúde junto de vários diversos públicos.

O MPms assume-se, e tem vindo a ser reconhecido, como um coletivo e um movimento social na saúde em Portugal. Esse reconhecimento fica a dever-se, em grande medida, à estratégia de informação e comunicação adotada, assente, fundamentalmente, na internet, em detrimento do recurso aos meios de comunicação tradicionais, cujo grau de profissionalização exigido, ao não existir no seio do projeto, implicaria perdas significativas na visibilidade e ampliação dos objetivos traçados inicialmente.

\section{O recurso à internet no âmbito do MAIS PARTICIPAÇÃO, melhor saúde}

À exceção das reuniões presenciais do GT-MPms (duas por ano), a restante comunicação e interação, quer entre os membros do GT-MPms, quer com representantes de outras associações e demais atores da saúde, foi realizada mediante recurso às tecnologias de informação e comunicação online: correio eletrónico, redes sociais, sítio de internet e videochamadas.

O inquérito por questionário foi respondido por 78 organizações da área da saúde - maioritariamente associações de pessoas com doença $(63,2 \%)$ - e 618 cidadãos. A divulgação deste foi feita por correio eletrónico, através das redes sociais e também por correio terrestre, e a recolha de dados, em papel e online, atingiu uma taxa de resposta online de $87,2 \%$ por parte das organizações e $91,7 \%$ por parte dos cidadãos.

A Carta para a Participação Pública em Saúde (Mais participação, melhor saúde, 2016), um dos instrumentos fundamentais do ativismo desenhado pelo MPms, depois de desenvolvida a versão inicial pelo GT-MPms, foi sujeita a divulgação e recolha de contributos junto de mais de 200 organizações na área da saúde em Portugal e centenas de individualidades ligadas à saúde e/ou à participação pública, apenas com recurso ao correio eletrónico e à divulgação através da internet e redes sociais. Todo o processo de subscrição da Carta assentou no recurso às mesmas tecnologias, tendo resultado num elevado número de signatários: 82 organizações - maioritariamente associações de pessoas com doença - e 30 personalidades com reconhecido mérito nas áreas da saúde e da participação pública ${ }^{6}$ Também a divulgação e comunicação do Fórum MAIS PARTICIPAÇÃO, melhor saúde, assim como a mobilização dos diversos atores da saúde neste âmbito, foram feitas através de correio eletrónico e das redes sociais, designadamente através da criação de um evento no Facebook que alcançou 14 mil utilizadores, teve 1100 visualizações e 269 respostas "Vou" e "Com interesse". O formulário de inscrição disponibilizado na internet foi utilizado por $91,6 \%(n=175)$ das pessoas inscritas no Fórum.

A petição promovida pelo MPms, que surge neste contexto como um elemento fundamental, e com potencial impacto no curso das ações futuras do projeto em análise neste artigo, foi criada através de um serviço gratuito de petições online ${ }^{7}$, tendo 
recolhido, entre setembro de 2016 e março de 2016, 2854 assinaturas, representando $94,5 \%$ do total de assinaturas recolhidas (as restantes foram recolhidas em papel). Desta forma, e relembrando a parca existência de espaços convencionais para efetivar a participação em saúde em Portugal (Matos, 2016), a petição veio a afirmar-se como uma ferramenta essencial no âmbito dos objetivos do projeto, concretizando uma das funções anteriormente identificadas por Tibúrcio (2007), designadamente o pedido dirigido aos poderes públicos no sentido de implementar a efetivação do direito de participação pública na definição de políticas públicas de saúde em Portugal. Esta ação concreta, embora considerada pela literatura analisada como uma forma de participação não convencional, pelo número de assinaturas que mobilizou e a articulação que estabeleceu com a Carta da Participação Pública, veio não só demonstrar a sua legitimidade enquanto ferramenta de participação (Della Porta, 2003; Meirinho, 2004), como demonstrou potencial de influência no âmbito da agenda política nacional. Sobre isto, importa salientar que, em Portugal, uma petição subscrita por um mínimo de 1000 cidadãos é, obrigatoriamente, publicada no Diário da Assembleia da República e, quando subscrita por mais de 4000 cidadãos, esta é apreciada em Plenário da Assembleia. Tendo ultrapassado as 1000 assinaturas, esta petição (em articulação com a Carta) cumpriu já o objetivo de colocar o assunto na participação pública em saúde na agenda política nacional, podendo vir a revestir-se de um potencial transformador mais vasto se forem ultrapassadas as 4000 assinaturas da petição, a qual se encontra ainda a decorrer.

Entre as redes sociais utilizadas, o Facebook assumiu preponderância na estratégia de comunicação adotada do projeto, não só por ser utilizado pela quase totalidade dos internautas portugueses utilizadores de redes sociais $(98,0 \%$ ) (Cardoso et al., 2014), mas também por ter várias funcionalidades disponíveis e fáceis de utilizar. Além disso, a maioria das associações portuguesas de pessoas com doença tem página nesta rede social. O número de "Gostos" da Página MPms (@participacaosaude), criada em 19 de outubro de 2016, cresceu, em média, a um ritmo de 27 novos "Gostos" por mês, entre novembro de 2015 e setembro de 2016, mês que antecedeu o Fórum MAIS PARTICIPAÇÃO, melhor saúde. Entre setembro e novembro de 216, o número de "Gostos" cresceu $67,0 \%$, tendo mantido, desde aí, uma taxa de novos "Gostos" superior à registada antes da realização do Fórum, num total de 1627 Gostos.

O crescimento do número de "Gostos" tem sido acompanhado também por uma melhoria contínua do desempenho da página no Facebook (quadro 1), onde são: i) publicados conteúdos próprios, tendo por base a Carta para a Participação Pública em Saúde, as 10 prioridades para promover a participação pública em saúde, a petição e a participação em reuniões científicas e conferências sobre saúde; e ii) publicados e partilhados conteúdos relacionados com a participação pública em saúde e outros com potencial interesse para as pessoas com doença e as suas associações.

Gráfico $1 \triangleright$ Evolução de "Gostos" da página MPms no Facebook

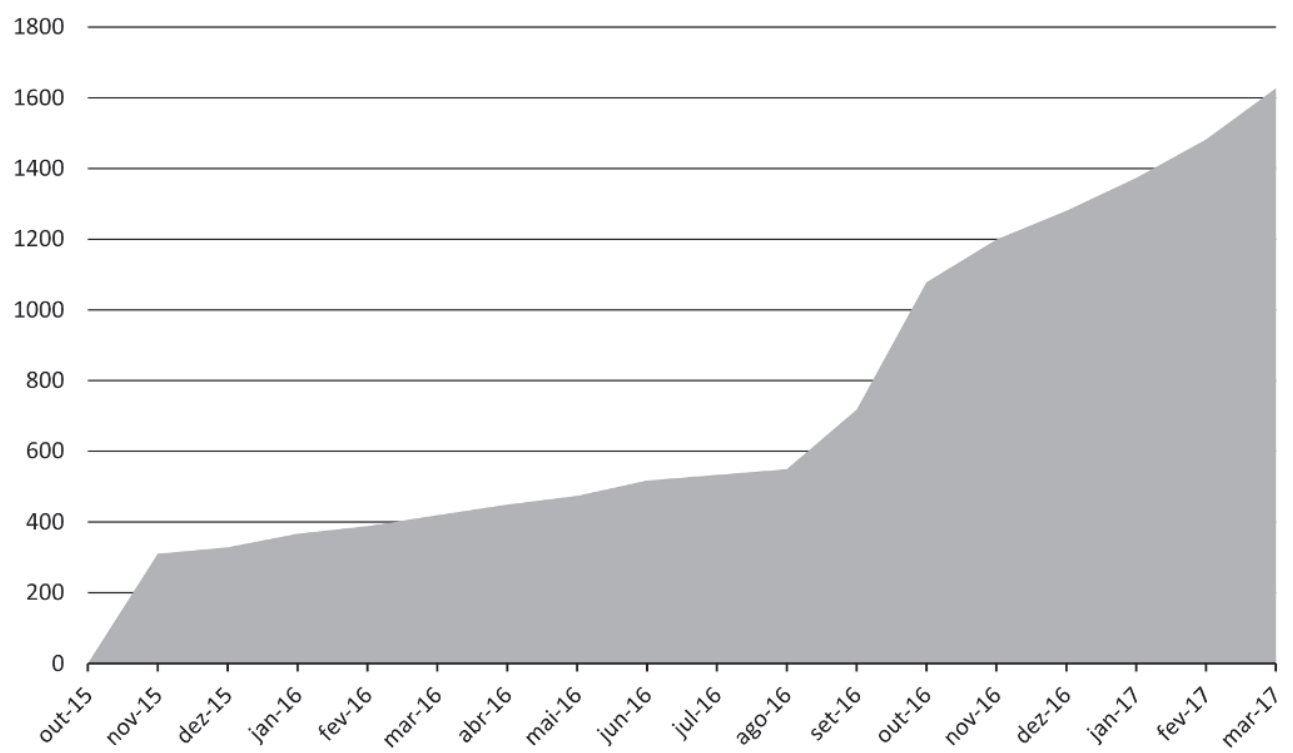

Fonte: Elaboração própria com base nas estatísticas da página MPms no Facebook. 
Quadro $1 \triangleright$ Resultados da Página MPms no Facebook

\begin{tabular}{l|c|c}
\hline \multicolumn{1}{c|}{ Resultados } & $\begin{array}{c}\text { Últimos 7 dias } \\
\mathbf{2 3} \text { a 29-mar-2017) }\end{array}$ & $\begin{array}{c}\text { Últimos 28 dias } \\
\text { (2 a 29-mar-2017) }\end{array}$ \\
\hline Ações na Página & $2(-33 \%)$ & $12(+140 \%)$ \\
\hline Visualizações da Página & $133(+533 \%)$ & $392(+6433 \%)$ \\
\hline Gostos da Página & $49(+1533 \%)$ & $145(+7150 \%)$ \\
\hline Alcance & $3764(-62 \%)$ & $40752(+51 \%)$ \\
\hline Interações com a publicação & $3292(+72 \%)$ & $7891(+102 \%)$ \\
\hline Vídeos & $63(+600 \%)$ & $190(+764 \%)$ \\
\hline
\end{tabular}

Fonte: Elaboração própria com base nas estatísticas da página MPms no Facebook.

Para os resultados obtidos em termos de desempenho da página Facebook, muito contribuiu o Fórum realizado e, posteriormente, também a participação em reuniões científicas e conferências sobre saúde, com as publicações com fotografias e vídeos a suscitarem maior envolvimento, muito em linha com a ideia da internet ao serviço da capacitação para a saúde tal defendida por Espanha (2013).

Comparativamente com outras páginas de associações que integram o GT-MPms, e apesar do número de "Gostos" inferior, a página do MPms teve, na semana em análise, um desempenho semelhante em termos de envolvimento, medido pela interação com a página (reações, comentários e partilhas).

As mulheres representam mais de $2 / 3$ das pessoas que gostam da página ("fãs"; $70 \%$ ) e das pessoas envolvidas ( $72 \%)$, um valor também semelhante à proporção de mulheres que responderam ao inquérito (71\%). A distribuição etária das pessoas que gostam da página e que responderam ao inquérito apresenta um pico entre os 35 e os 44 anos (32\% e $28 \%$, respetivamente). No entanto, no universo das pessoas envolvidas ( $56,0 \%$ do total de pessoas que gostam da página), a distribuição etária é mais uniforme, com maior representação das pessoas com 55 ou mais anos ( $42 \%$ versus $17 \%$ entre as pessoas que gostam da página). Estes resultados estão em linha com os resultados do último Inquérito Nacional de Saúde (INE, 2016), que mostra serem as mulheres quem mais procura cuidados de saúde e que a prevalência de doença crónica aumenta com a idade, o que sugere que estas variáveis podem influenciar o envolvimento no Facebook.

O Twitter, utilizado por apenas $9,0 \%$ dos internautas portugueses utilizadores de redes sociais (Cardoso et al., 2014), foi utilizado apenas esporadicamente, com maior relevo e interesse para a comunicação sobre iniciativas internacionais e em língua inglesa.

O MPms tem ainda uma página com informação sobre o projeto $^{8}$ e outra sobre o Fórum MAIS PARTICIPAÇÃO, melhor saúde ${ }^{9}$, ambas alojadas no sítio de internet da associação de pessoas com doença promotora inicial do MPms.

\section{Conclusão}

A internet constituiu uma alavanca fundamental em todo o processo de constituição e afirmação do MPms enquanto coletivo e movimento social atuante na área da saúde em Portugal, desde a comunicação entre as associações envolvidas e com todos os restantes atores, até à convocação para eventos presenciais, passando pela divulgação do MPms e das atividades realizadas ou a recolha de informação por inquérito. Além de os custos associados serem reduzidos, a facilidade de acesso e de utilização,

Quadro $2 \triangleright$ Desempenho no Facebook

\begin{tabular}{l|c|c|c}
\hline Página & Total de Gostos & Publicações da semana & Interação esta semana* \\
\hline MPms & $1,6 \mathrm{~K}$ & 9 & 113 \\
\hline Associação A & $2,2 \mathrm{~K}$ & 8 & 38 \\
\hline Associação B & $2,4 \mathrm{~K}$ & 2 & 17 \\
\hline Associação C & $2,4 \mathrm{~K}$ & 0 & 0 \\
\hline Associação D & $3,2 \mathrm{~K}$ & 15 & 151 \\
\hline Associação E & $3,8 \mathrm{~K}$ & 6 & 86 \\
\hline
\end{tabular}

* Reações, comentários e partilhas

Fonte: Elaboração própria com base nas estatísticas da página MPms no Facebook. 
Gráfico 2. "Fãs" e pessoas envolvidas na Página MPms no Facebook

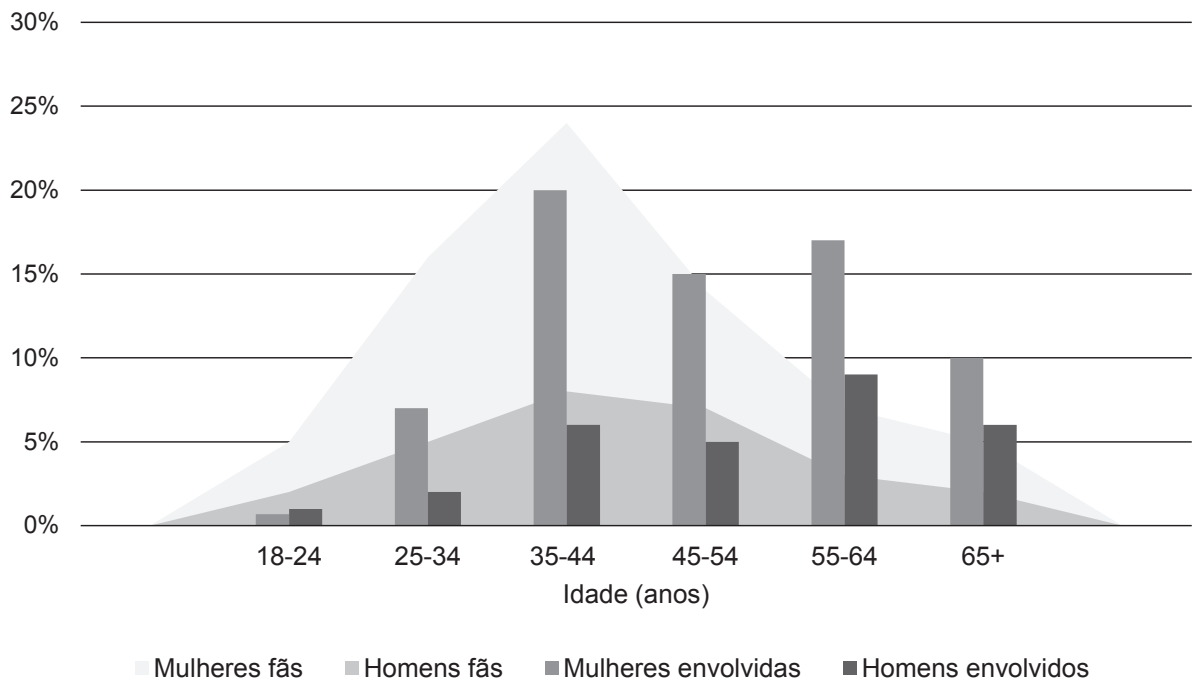

Fonte: Elaboração própria com base nas estatísticas da página MPms no Facebook.

aliada à possibilidade de interação à distância, tornam a internet uma ferramenta fundamental para uma iniciativa coletiva sem fins lucrativos, com objetivos de alcance e envolvimento públicos num contexto nacional em que a participação pública em saúde não é ainda uma prática regular e efetiva, apesar de consignada juridicamente como direito a exercer pelos cidadãos.

Além de ter contribuído para o sucesso da implementação do projeto MPms, a internet, em particular a rede social Facebook, foi o que permitiu dar a conhecer algumas das mais importantes reivindicações das várias organizações que constituem o GT-MPms. Ao constituir-se como espaço privilegiado de divulgação de informação do MPms, a página de Facebook do projeto funcionou também como meio de partilha, com o público em geral, de informação sobre saúde em geral, oportunidades de participação e outras iniciativas na área da participação e saúde, quer nacionais quer internacionais. Esta dinâmica funcionou como força motriz de uma nova rede social e ativista que se mantém em funcionamento.

\section{Notas}

1 Trabalho financiado pela Fundação para a Ciência e a Tecnologia (SFRH/BPD/94178/2013).

2 Da primeira Constituição, de 1822, à que está atualmente em vigor, todas as constituições portuguesas consagraram o direito de petição nos seus textos (Tibúrcio, 2007).

3 Com destaque para: a) falta de mecanismos formais de participação; b) insuficiência dos meios humanos e financeiros nas associações para influenciarem as políticas; c) não é entendido como relevante a simples vivência da doença enquanto aporte nos processos decisórios, já que nestes se esperam "técnicos", não doentes, inexistindo o consequente reconhecimento legal do doente "perito"; d) falta de colaboração e coordenação de recursos e esforços entre associações da mesma área; e) falta de representatividade a nível de "associações-chapéu"; e f) falta de reconhecimento, ao nível de uma participação significativa, com reflexo nos resultados dos doentes como elementos-chave para o desenvolvimento dos programas e políticas pelos seus responsáveis e da importância do seu contributo (Ferreira et al., 2016: 88).

4 De áreas representativas da política pública de saúde e da prestação de cuidados no SNS: comportamentos aditivos e dependências, diabetes, doenças cérebro-cardiovasculares, doenças oncológicas, doenças raras, doenças respiratórias, doenças reumáticas, infeção VIH/ /SIDA e saúde mental.

5 O MPms tem também a participação e a supervisão científica do Centro de Estudos Sociais (Universidade de Coimbra).

6 Atuais e ex-deputados, ex-ministros da Saúde, profissionais de saúde, professores universitários e investigadores e ativistas na área da saúde.

7 www.peticaopublica.com.

8 www.gatportugal.org/projetos/mais-participacao-melhor-saude_12.

9 http://www.gatportugal.org/eventos/forum-mais-participacao-melhor-saude_27.

\section{Referências bibliográficas}

BROWN, P. e S. Zavestoski, (2005), Social Movements in Health, Oxford, Blackwell.

CARDOSO, G. (1998), Para uma sociologia do ciberespaço: comunidades virtuais em português, Oeiras, Celta Editora. 
CARDOSO, G.; S. Mendonça, et al. (2014), A internet em Portugal - Sociedade em rede 2014, Lisboa, Publicações OberCom. Disponível em http://obercom.pt/wp-content/uploads/2016/06/A-Internet-em-Portugal-Sociedade-em-Rede-2014.pdf.

CASTELLS, M. (2004), A galáxia internet - Reflexões sobre internet, negócios e sociedade, Lisboa, Fundação Calouste Gulbenkian.

DALTON, R. (1988), Citizen Politics in Western Democracies, Chatham/NJ, Chatham House.

DELLA PORTA, D. (2003), Introdução à ciência política, Lisboa, Editorial Estampa.

DELLA PORTA, D. (2007), "La democrazia partecipativa e I movimenti sociali. Micro e macro-dinamiche", in B. Gelli (ed.), Le nuove forme di partecipazione, Roma, Carocci, pp. 73-86.

DELLA PORTA, D. e M. Diani (1999), Social Movements: An introduction, Cornwall, Blackwell Publishing.

ESCOVAL, A.; M. Lopes e P. L. Ferreira (orgs.) (2011), Da repressão da crise para a governação prospectiva da saúde - Relatório de Primavera, Coimbra, Mar da Palavra.

ESPANHA, R. (2013), Informação e saúde, Lisboa, Fundação Francisco Manuel dos Santos.

FERREIRA, P. L.; J. A. Silva, et al. (orgs.) (2016), Saúde. Procuram-se novos caminhos - Relatório de Primavera, Coimbra, Mar da Palavra.

FILIPE, A. M.; M. Roriz, et al. (2014), "Coletivos sociais na saúde: o ativismo em torno das doenças raras e do parto em Portugal", in M. Serapioni e A. R. Matos (orgs.), Saúde, participação e cidadania. Experiências do Sul da Europa, Coimbra, Almedina, pp. 173-191.

GREENWOOD, D. J. e M. Levin (2007), Introduction to Action Research. Social Research for Social Change, Londres, Sage.

HABERMAS, J. (1973), Theory and Practice, Londres, Polity Press.

INE - Instituto Nacional de Estatística (2016), Inquérito Nacional de Saúde 2014, Lisboa, INE.

MAIS PARTICIPAÇÃO, MELHOR SAÚDE (2016), Carta para a Participação Pública em Saúde. Disponível em: http://www.gatportugal.org/public/uploads/ projetos/MAIS_Participacao/Carta_para_a_Participacao_Publica_em_Saude.pdf.
MATOS, A. R. (2016), "'Eu participo, tu participas... nós protestamos': ações de protesto, democracia e participação em processos de decisão", O Público e o Privado, (27), pp. 119-137.

MEIRINHO, M. M. (2004), Participação política e democracia - O caso português (1976-2000), Lisboa, Instituto Superior de Ciências Sociais e Políticas.

MENDES, J. M. e A. M. Seixas (2005), "Acção colectiva e protesto em Portugal: os movimentos sociais ao espelho dos media (1992-2002)", Revista Crítica de Ciências Sociais, 72, pp. 99-127.

SAKELLARIDES, C. ; L. Nunes, et al. (2009), 10-30 anos: razões para continuar - Relatório de Primavera, Coimbra, Mar da Palavra.

SERAPIONI, M.; P. L. Ferreira e P. Antunes (2014), "Participação em saúde: conceitos e conteúdos", Notas Económicas, 40, pp. 26-40.

STRINGER, E. T. (2014), Action Research, Londres, Sage.

THOMAS, R. (2006), Health Communication, Nova Iorque, Springer.

TIBÚRCIO, T. (2007), O direito de petição perante a Assembleia da República, dissertação de mestrado em Ciência Política, Lisboa, Instituto Superior de Ciências do Trabalho e da Empresa.

TILLY, C. (2004), "Contentious Choices", Theory and Society, 33 (3/4), pp. 473-481.

WHO (1978), Alma-Ata 1978. Primary Health Care: Report of the Conference, Genebra, WHO.

WHO (1981), Global Strategy for Health for All by the Year 2000, Genebra, WHO.

WHO (1998), Health21 - Health for All in the 21 $1^{\text {st }}$ Century, Copenhaga, WHO.

WHO (2002), Community Participation in Local Health Care and Sustainable Development: Approaches and Techniques, Genebra, WHO.

WINKELMAN, W. J. e C. W. Choo (2003), "ProviderSponsored Virtual Communities for Chronic Patients: Improving Health Outcomes Through Organizational Patient-Centred Knowledge Management", Health Expectations, 6 (4), pp. 352-358.

WOOLLEY, P. e M. Peterson (2012), "Efficacy of a Health-Related Facebook Social Network Site on Health-Seeking Behaviors", Social Marketing Quarterly, 18 (1), pp. 29-39.

Recebido a 31/03/2017. Aceite para publicação a 24/10/2017.

Sofia Crisóstomo (sofiacrisostomo@gmail.com). Instituto Universitário de Lisboa (ISCTE-IUL), Centro de Investigação e Estudos de Sociologia (CIES-IUL) \& GAT - Grupo de Ativistas em Tratamentos. Edifício ISCTE, Av. das Forças Armadas, 1649-026 Lisboa, Portugal.

Ana Raquel Matos (amatos@ces.uc.pt). Universidade de Coimbra, Centro de Estudos Sociais (CES). Colégio de S. Jerónimo, Largo D. Dinis, Apartado 3087, 3000-995 Coimbra, Portugal.

Marta Borges (martaleiriaborges@gmail.com). GAT - Grupo de Ativistas em Tratamentos. Av. de Paris, 4, 1.0 direito, 1000-228 Lisboa, Portugal.

Margarida Santos (margarida_tpc@yahoo.co.uk). Instituto Universitário de Lisboa (ISCTE-IUL), Centro de Investigação e Intervenção Social (CIS-IUL) \& GAT - Grupo de Ativistas em Tratamentos. Edifício ISCTE, Av. das Forças Armadas, 1649-026 Lisboa, Portugal. 